\title{
Blood pressure and mortality in patients with type 2 diabetes and a recent coronary event in the ELIXA trial
}

\author{
Magnus O. Wijkman ${ }^{1,2^{*}} \mathbb{D}$, Brian Claggett ${ }^{1}$, Rafael Diaz ${ }^{3}$, Hertzel C. Gerstein ${ }^{4}$, Lars Køber ${ }^{5}$, Eldrin Lewis ${ }^{6}$, \\ Aldo P. Maggioni ${ }^{7,8}$, Emil Wolsk ${ }^{5}$, David Aguilar ${ }^{9}$, Rhonda Bentley-Lewis ${ }^{10}$, John J. McMurray ${ }^{11}$, \\ Jeffrey Probstfield ${ }^{12}$, Matthew Riddle ${ }^{13}$, Jean-Claude Tardif ${ }^{14}$, Scott D. Solomon ${ }^{1}$ and Marc A. Pfeffer ${ }^{1}$
}

\begin{abstract}
Background: The relationship between blood pressure and mortality in type 2 diabetes (T2DM) is controversial, with concern for increased risk associated with excessively lowered blood pressure.

Methods: We evaluated whether prior cardiovascular disease (CVD) altered the relationship between baseline blood pressure and all-cause mortality in 5852 patients with T2DM and a recent acute coronary syndrome (ACS) who participated in the ELIXA (Evaluation of Lixisenatide in Acute Coronary Syndrome) trial. Risk of death was assessed in Cox models adjusted for age, sex, race, heart rate, BMI, smoking, diabetes duration, insulin use, HbA1c, eGFR, brain natriuretic peptide (BNP), urine albumin/creatinine ratio, treatment allocation and prior coronary revascularization.

Results: Although overall there was no significant association between systolic blood pressure (SBP) and mortality (hazard ratio per $10 \mathrm{mmHg}$ lower SBP 1.05 (95\% Cl 0.99-1.12) P=0.10), lower SBP was significantly associated with higher risk of death (hazard ratio per $10 \mathrm{mmHg}$ lower SBP $1.13(95 \% \mathrm{Cl} 1.04-1.22) \mathrm{P}=0.002)$ in 2325 patients with additional CVD (index ACS+ at least one of the following prior to randomization: myocardial infarction other than the index ACS, stroke or heart failure). In 3527 patients with only the index ACS no significant association was observed (hazard ratio per $10 \mathrm{mmHg}$ lower SBP $0.95(0.86-1.04) \mathrm{P}=0.26$; P for interaction 0.005).
\end{abstract}

Conclusions: The association between blood pressure and mortality was modified by additional CVD history in patients with type 2 diabetes and a recent coronary event. When blood pressures measured after an acute coronary event are used to assess the risk of death in patients with type 2 diabetes, the cardiovascular history needs to be taken into consideration.

Trial registration ClinicalTrials.gov number NCT01147250, first posted June 22, 2010

Keywords: Diabetes mellitus, Coronary artery disease, Blood pressure

\section{Background}

Elevated blood pressure is considered an important additive risk factor in patients with type 2 diabetes, augmenting the already heightened risk for morbidity and

\footnotetext{
*Correspondence: mwijkman@bwh.harvard.edu; magnus.wijkman@liu.se ${ }^{1}$ Cardiovascular Division, Brigham \& Women's Hospital, Harvard Medical School, 75 Francis Street, Boston, MA 02115, USA
}

Full list of author information is available at the end of the article mortality in these patients [1]. However, there is ongoing controversy regarding the optimal blood pressure treatment targets [2], and current guidelines provide differing recommendations [3-5]. In patients with type 1 diabetes, a linear relationship between higher systolic blood pressure and higher risk for stroke has been observed even below blood pressure levels recommended in more strict guidelines [6]. Observational data have shown

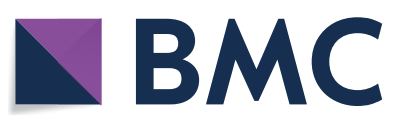

(c) The Author(s) 2020. This article is licensed under a Creative Commons Attribution 4.0 International License, which permits use, sharing, adaptation, distribution and reproduction in any medium or format, as long as you give appropriate credit to the original author(s) and the source, provide a link to the Creative Commons licence, and indicate if changes were made. The images or other third party material in this article are included in the article's Creative Commons licence, unless indicated otherwise in a credit line to the material. If material is not included in the article's Creative Commons licence and your intended use is not permitted by statutory regulation or exceeds the permitted use, you will need to obtain permission directly from the copyright holder. To view a copy of this licence, visit http://creativeco mmons.org/licenses/by/4.0/. The Creative Commons Public Domain Dedication waiver (http://creativecommons.org/publicdomain/ zero/1.0/) applies to the data made available in this article, unless otherwise stated in a credit line to the data. 
linear relationships between higher blood pressure and higher cardiovascular risk in patients with type 2 diabetes without a history of cardiovascular disease (CVD) [7], whereas U-shaped relationships have been described in patients with type 2 diabetes and established CVD or in patients with a high-risk profile [8-12]. Similar concerns for higher cardiovascular risk with excessively lowered systolic or diastolic blood pressures have been raised for patients with established coronary artery disease $[13,14]$. However, little is known about the associations between blood pressure measured after an acute coronary event and subsequent risk of death in patients with type 2 diabetes, and whether a history of additional CVD may have an impact on the association between blood pressure levels and mortality in these patients. Therefore, the aims of this study were twofold: to characterize the overall relationships between baseline blood pressure levels and all-cause mortality in patients with type 2 diabetes who, as required for entry to the ELIXA (Evaluation of Lixisenatide in Acute Coronary Syndrome) trial, had a recent acute coronary syndrome (ACS), and to ascertain whether these relationships were influenced by prior CVD status.

\section{Methods}

\section{Patients}

The design, patient characteristics and cardiovascular outcomes of the ELIXA trial (ClinicalTrials.gov number NCT01147250) have been published previously $[15,16]$. In brief, ELIXA was a randomized placebo-controlled double-blind multi-center trial which evaluated the cardiovascular safety and outcomes of treatment with lixisenatide, a glucagon-like peptide 1-receptor agonist in 6068 patients with type 2 diabetes who had recently experienced an ACS. Exclusion criteria were age of less than 30 years, glycated hemoglobin level of less than 5.5\% or more than $11.0 \%$, estimated glomerular filtration rate (eGFR) of less than $30 \mathrm{ml} / \mathrm{min} / 1.73 \mathrm{~m}^{2}$, coronary artery by-pass graft surgery for the qualifying event, percutaneous coronary intervention within 15 days prior to the screening visit, planned coronary revascularization within 90 days after the screening visit, or inability to provide written informed consent. There were no exclusion criteria related to blood pressure levels. The median follow-up time was 25 months. Lixisenatide (or volumematched placebo) was administered as sub-cutaneous injections, with a maximal daily dose of $20 \mu \mathrm{g} /$ day. For the purpose of this secondary analysis, 216 patients were excluded due to missing baseline data (reasons for exclusion are presented in Additional file 1: Table S1) and this yielded a study cohort of 5852 patients. These patients were divided in two groups: those who prior to randomization had a history of at least one of the following: myocardial infarction other than the index ACS, stroke or heart failure ("additional CVD"), and those who did not have a history of any of the above prior to randomization ("index ACS only").

\section{Measurements of blood pressure and left ventricular ejection fraction}

Baseline blood pressure was assessed as the mean of screening and randomization blood pressures. The median number of days between the screening and randomization visits was seven (interquartile range [IQR] 7-8 days). The study instructions stated that blood pressure measurements should be performed with the patient in the supine position, after the patient had rested comfortably for at least $5 \mathrm{~min}$. Pulse pressure (PP) was calculated as systolic blood pressure (SBP) minus diastolic blood pressure (DBP). Throughout the trial, the antihypertensive medications could be adjusted according to local practice guidelines, as deemed appropriate by the patient's treating physicians. When available, left ventricular ejection fraction (LVEF) was reported by the enrolling sites on an electronic case report form, as described previously [17].

\section{Statistics}

Descriptive data are presented as mean \pm standard deviation (SD) and/or as median [IQR] for continuous variables. Between-group differences were tested for statistical significance with Student's t-test, Wilcoxon rank sum test, analysis of variance or Kruskal-Wallis test for continuous variables, and with Chi square test for categorical variables. The incidence of death was plotted against SBP, DBP, and PP, using restricted cubic spline curves with three knots. The associations were tested for overall statistical significance and for evidence of statistically significant non-linearity based on the Poisson distributions of the incidence rates. A proportional hazards Cox regression model was used to calculate the hazard ratio (HR) for death with 95\% confidence intervals (CI) associated with a blood pressure difference of $10 \mathrm{mmHg}$. For significant associations that also exhibited evidence of significant non-linearity, piecewise Cox regression was used to determine hazard ratios separately for the lower and the upper parts of the spline curves. All spline curves and Cox regressions were adjusted for randomization group and for history of coronary revascularization prior to randomization and for the following potential baseline confounders, that were selected from a previously published risk prediction model [18]: age, sex, self-reported race (Asian/Black or African American/White/Other), heart rate, body mass index (BMI), smoking status (Never/Former/Current), duration of diabetes, glycated 
hemoglobin A1c, use of insulin, estimated glomerular filtration rate (eGFR), the logarithm of the urinary albumin to creatinine ratio and the logarithm of the braintype natriuretic peptide (BNP) level. By study design, all patients in ELIXA were included after hospitalization for an ACS. In this analysis, we first analyzed the relationships between blood pressure and mortality in all patients, and then repeated the analyses separately in patients without a history of additional CVD prior to randomization ("index ACS only") and in patients who prior to randomization did have a history of at least one of the following: myocardial infarction other than the index ACS, stroke, or heart failure ("additional CVD"). Interactions between blood pressure and additional CVD history were tested for statistical significance with stratified Cox regression. A sensitivity analysis was also performed in patients who did not have heart failure at baseline, and another sensitivity analysis in which we additionally adjusted for LVEF was performed in the 3957 patients where this information was available. When testing for statistical significance, we considered $\mathrm{P}$ values $<0.05$ as significant. No correction was made for multiple testing. Statistical analyses were performed in STATA, version 14 (College Station, TX).

\section{Results}

\section{Patient characteristics}

Overall, the mean age was $60.3 \pm 9.7$ years and 1779 patients $(30.4 \%)$ were women. The median number of days between the index ACS and the first blood pressure measurement was 52 [IQR: 30-86 days]. Baseline SBP was less than $140 \mathrm{mmHg}$ in 4256 patients (72.7\%) and baseline DBP was less than $90 \mathrm{mmHg}$ in 5273 patients (90.1\%). There were 2325 patients (39.7\%) who prior to randomization had a history of additional CVD (either myocardial infarction other than the index ACS $(\mathrm{n}=1341)$ and/or stroke $(\mathrm{n}=314)$ and/or heart failure $(\mathrm{n}=1317))$. Baseline patient characteristics are presented in Table 1 according to prior CVD status, and in Table 2 according to tertiles of SBP. Despite having lower SBP and lower DBP, patients in the lowest tertile of SBP were less likely to use calcium channel blockers, angiotensin receptor blockers and diuretics (Table 2). The baseline distributions of SBP and DBP are shown graphically in Fig. 1 according to prior CVD status. At baseline, the mean SBP was $130 \pm 16$ [median 130, IQR: $120-140$ ] $\mathrm{mmHg}$ in patients with index ACS only and $132 \pm 16$ [median 130, IQR: $121-141] \mathrm{mmHg}$ in patients with additional CVD, $\mathrm{P}<0.001$. The baseline mean DBP was $78 \pm 9$ [median 78, IQR: 72-84] $\mathrm{mmHg}$ in patients with index ACS only and $78 \pm 9$ [median 79, IQR: 72-84] $\mathrm{mmHg}$ in patients with additional CVD, $\mathrm{P}=0.95$.

\section{Blood pressure and mortality}

Overall, there were 421 deaths among the 5852 patients in this analysis (3.3 deaths per 100 patient-years). There were more deaths among the 2325 patients with additional CVD (258 deaths, 5.0 deaths per 100 patient-years) than among the 3527 patients with index ACS only (163 deaths, 2.1 deaths per 100 patient-years) $\mathrm{P}<0.001$. The number of deaths did not differ significantly between tertiles of SBP (first tertile: 136 deaths/2008 patients, 3.1 deaths per 100 patient-years; second tertile: 141 deaths/1909 patients, 3.3 deaths/100 patient-years; third tertile: 144 deaths/1935 patients, 3.4 deaths/100 patientyears) $\mathrm{P}=0.66$.

Out of the 421 deaths, 307 were cardiovascular deaths (2.4 cardiovascular deaths per 100 patient-years). Overall, there was no significant association between SBP and mortality (Fig. 2, Table 3). However, the relationship between SBP and mortality differed according to prior CVD status (P for interaction 0.005) such that in patients with additional CVD, lower SBP was associated with higher mortality (HR per $10 \mathrm{mmHg}$ lower SBP: 1.13 (1.04-1.22) $\mathrm{P}=0.002$ ) whereas in patients with index ACS only there was no significant relationship between SBP and mortality (Fig. 2, Table 3). For DBP, overall, there was a significant, non-linear, relationship between DBP and mortality such that for DBP values lower than $80 \mathrm{mmHg}$, lower DBP was associated with higher mortality (HR per $10 \mathrm{mmHg}$ lower DBP: 1.30 (1.11-1.51) $\mathrm{P}=0.001$ ), but for DBP values of $80 \mathrm{mmHg}$ and higher, no significant relationship was observed (Fig. 2, Table 3). The association between DBP and mortality also differed according to prior CVD status (P for interaction 0.004). In patients with additional CVD, the association changed from non-linear to linear, such that lower DBP was associated with higher mortality across the entire range of DBP values (HR per $10 \mathrm{mmHg}$ lower DBP: 1.30 (1.131.49) $\mathrm{P}<0.001)$ whereas in patients with index ACS only, there was no significant association between DBP and mortality (Fig. 2, Table 3). For PP, there was no significant association with mortality and no significant interaction between prior CVD and PP (Fig. 2, Table 3).

\section{Sensitivity analysis in patients without heart failure}

After excluding 1317 patients with a diagnosis of heart failure at baseline, we performed a sensitivity analysis in the remaining 4535 patients (3527 with index ACS only and 1008 with additional CVD). There were 77 deaths in the group with additional CVD (3.5 deaths per 100 patient-years) and 163 deaths in the group with index ACS only (2.1 deaths per 100 patient-years) $\mathrm{P}<0.001$. As in the original cohort, there was no significant overall association between SBP and mortality (Additional 
Table 1 Baseline characteristics by prior additional CVD status

\begin{tabular}{|c|c|c|c|}
\hline & $\begin{array}{l}\text { Index ACS only } \\
n=3527\end{array}$ & $\begin{array}{l}\text { Additional CVD } \\
\mathrm{n}=2325\end{array}$ & $P$ \\
\hline Age (years) & $59.0 \pm 9.6$ & $62.3 \pm 9.3$ & $<0.001$ \\
\hline Female, n (\%) & $980(28 \%)$ & $799(34 \%)$ & $<0.001$ \\
\hline Race, n (\%) & & & $<0.001$ \\
\hline Asian & $582(17 \%)$ & $176(8 \%)$ & \\
\hline Black or African American & $116(3 \%)$ & $88(4 \%)$ & \\
\hline White & $2501(71 \%)$ & 1907 (82\%) & \\
\hline Other & $328(9 \%)$ & $154(7 \%)$ & \\
\hline Systolic blood pressure (mmHg) & $130 \pm 16$ & $132 \pm 16$ & $<0.001$ \\
\hline Diastolic blood pressure (mmHg) & $78 \pm 9$ & $78 \pm 9$ & 0.95 \\
\hline Pulse pressure (mmHg) & $52 \pm 13$ & $54 \pm 13$ & $<0.001$ \\
\hline Heart rate (bpm) & $70 \pm 9$ & $70 \pm 9$ & 0.89 \\
\hline $\mathrm{BMI}\left(\mathrm{kg} / \mathrm{m}^{2}\right)$ & $29.7 \pm 5.7$ & $30.7 \pm 5.6$ & $<0.001$ \\
\hline Diabetes duration (years) & $8.5 \pm 7.8$ & $10.4 \pm 8.7$ & $<0.001$ \\
\hline HbA1c (\%) & $7.7 \pm 1.3$ & $7.7 \pm 1.3$ & 0.48 \\
\hline $\mathrm{eGFR}\left(\mathrm{ml} / \mathrm{min} / 1.73 \mathrm{~m}^{2}\right)$ & $79 \pm 21$ & $71 \pm 21$ & $<0.001$ \\
\hline Albuminuria (mg/g) & & & $<0.001$ \\
\hline$<30$ (normal) & $2697(77 \%)$ & $1633(70 \%)$ & \\
\hline$\geq 30-<300$ (micro) & $631(18 \%)$ & $494(21 \%)$ & \\
\hline$\geq 300$ (macro) & $184(5 \%)$ & $191(8 \%)$ & \\
\hline $\mathrm{BNP}(\mathrm{pg} / \mathrm{ml})$ median $[\mathrm{IQR}]$ & $90[44-176]$ & 138 [63-293] & $<0.001$ \\
\hline Smoking status, n (\%) & & & 0.005 \\
\hline Current & $421(12 \%)$ & $246(11 \%)$ & \\
\hline Former & $1646(47 \%)$ & 1019 (44\%) & \\
\hline Never & $1460(41 \%)$ & $1060(46 \%)$ & \\
\hline MI history other than index ACS, n (\%) & $0(0.0 \%)$ & $1341(58 \%)$ & NA \\
\hline Stroke history, n (\%) & $0(0.0 \%)$ & $314(14 \%)$ & NA \\
\hline Heart failure history, n (\%) & $0(0.0 \%)$ & $1317(57 \%)$ & NA \\
\hline Coronary revascularization history, n (\%) & $2527(72 \%)$ & $1554(67 \%)$ & $<0.001$ \\
\hline STEMI at index event, $\mathrm{n}(\%)$ & $1817(52 \%)$ & $756(33 \%)$ & $<0.001$ \\
\hline Left ventricular ejection fraction ${ }^{a}$ (percent) & $53 \pm 11$ & $48 \pm 13$ & $<0.001$ \\
\hline Insulin, n (\%) & $1239(35 \%)$ & $1042(45 \%)$ & $<0.001$ \\
\hline Statin, n (\%) & $3333(95 \%)$ & $2099(90 \%)$ & $<0.001$ \\
\hline Beta blocker, n (\%) & $2904(82 \%)$ & 2049 (88\%) & $<0.001$ \\
\hline Calcium channel blocker, n (\%) & $652(19 \%)$ & $629(27 \%)$ & $<0.001$ \\
\hline Diuretic, n (\%) & $1085(31 \%)$ & $1223(53 \%)$ & $<0.001$ \\
\hline ACE inhibitor, n (\%) & 2095 (59\%) & $1437(62 \%)$ & 0.07 \\
\hline ARB, n (\%) & $910(26 \%)$ & $645(28 \%)$ & 0.10 \\
\hline Alpha blocker, n (\%) & $136(4 \%)$ & $122(5 \%)$ & 0.011 \\
\hline Potassium sparing agents, n (\%) & $347(10 \%)$ & $508(22 \%)$ & $<0.001$ \\
\hline
\end{tabular}

Unless stated otherwise, values are mean $\pm \mathrm{SD}$ or $\mathrm{n}(\%)$

$A C E$ angiotensin converting enzyme, $A C S$ acute coronary syndrome, $A R B$ angiotensin receptor blocker, $B M I$ body mass index, $B N P$ brain-type natriuretic peptide, eGFR estimated glomerular filtration rate, HbA1c glycosylated hemoglobin, $H D L$ high density lipoprotein, LDL low density lipoprotein, MI myocardial infarction, STEMI ST segment elevation myocardial infarction

a Data available for 3957 patients for left ventricular ejection fraction (2352 in patients with index ACS only and 1605 in patients with additional CVD)

file 1: Table S2) and there was a significant interaction $(\mathrm{P}<0.001)$ between SBP and prior CVD. In patients with additional CVD, lower SBP remained significantly associated with higher mortality (HR per $10 \mathrm{mmHg}$ lower SBP $1.39(1.18-1.63) \mathrm{P}<0.001)$. For $\mathrm{DBP}$, the overall relationship with mortality remained non-linear as in the original cohort (Additional file 1: Table S2) and the association between DBP and mortality also 
Table 2 Baseline characteristics by tertiles of systolic blood pressure

\begin{tabular}{|c|c|c|c|c|}
\hline & $\begin{array}{l}\text { Tertile } 1 \mathrm{n}=2008 \\
\text { SBP } 74-124 \mathrm{mmHg}\end{array}$ & $\begin{array}{l}\text { Tertile } 2 \mathrm{n}=1909 \\
\mathrm{SBP}>124-136 \mathrm{mmHg}\end{array}$ & $\begin{array}{l}\text { Tertile } 3 n=1935 \\
S B P>136-225 \mathrm{mmHg}\end{array}$ & $\mathbf{P}$ \\
\hline Age (years) & $57.9 \pm 9.8$ & $60.5 \pm 9.3$ & $62.6 \pm 9.3$ & $<0.001$ \\
\hline Female, n (\%) & $503(25 \%)$ & $603(32 \%)$ & $673(35 \%)$ & $<0.001$ \\
\hline Race, n (\%) & & & & $<0.001$ \\
\hline Asian & $294(15 \%)$ & $274(14 \%)$ & $190(10 \%)$ & \\
\hline Black or African American & $52(3 \%)$ & $74(4 \%)$ & $78(4 \%)$ & \\
\hline White & $1444(72 \%)$ & $1447(76 \%)$ & $1517(78 \%)$ & \\
\hline Other & $218(11 \%)$ & $114(6 \%)$ & $150(8 \%)$ & \\
\hline Systolic blood pressure $(\mathrm{mmHg})$ & $114 \pm 8$ & $130 \pm 4$ & $149 \pm 11$ & NA \\
\hline Diastolic blood pressure $(\mathrm{mmHg})$ & $72 \pm 7$ & $79 \pm 7$ & $84 \pm 9$ & $<0.001$ \\
\hline Pulse pressure $(\mathrm{mmHg})$ & $42 \pm 7$ & $51 \pm 7$ & $65 \pm 12$ & NA \\
\hline Heart rate (bpm) & $71 \pm 9$ & $70 \pm 9$ & $70 \pm 10$ & 0.011 \\
\hline BMI $\left(\mathrm{kg} / \mathrm{m}^{2}\right)$ & $29.1 \pm 5.3$ & $30.4 \pm 5.8$ & $31.0 \pm 5.8$ & $<0.001$ \\
\hline Diabetes duration (years) & $8.4 \pm 8.0$ & $9.2 \pm 8.1$ & $10.3 \pm 9$ & $<0.001$ \\
\hline $\mathrm{HbA} 1 \mathrm{c}(\%)$ & $7.7 \pm 1.3$ & $7.7 \pm 1.3$ & $7.7 \pm 1.3$ & 0.33 \\
\hline $\operatorname{eGFR}\left(\mathrm{ml} / \mathrm{min} / 1.73 \mathrm{~m}^{2}\right)$ & $78 \pm 21$ & $76 \pm 21$ & $74 \pm 22$ & $<0.001$ \\
\hline Albuminuria (mg/g) & & & & $<0.001$ \\
\hline$<30$ (normal) & $1637(82 \%)$ & $1424(75 \%)$ & $1269(66 \%)$ & \\
\hline$\geq 30-<300$ (micro) & $297(15 \%)$ & $363(19 \%)$ & $465(24 \%)$ & \\
\hline$\geq 300$ (macro) & $67(3 \%)$ & $117(6 \%)$ & $191(10 \%)$ & \\
\hline BNP $(\mathrm{pg} / \mathrm{ml})$ median $[\mathrm{IQR}]$ & $106[49-234]$ & $100[47-203]$ & $111[54-226]$ & 0.006 \\
\hline Smoking status, n (\%) & & & & $<0.001$ \\
\hline Current & $248(12 \%)$ & $214(11 \%)$ & $205(11 \%)$ & \\
\hline Former & $1012(50 \%)$ & $789(41 \%)$ & $864(45 \%)$ & \\
\hline Never & $748(37 \%)$ & $906(48 \%)$ & $866(45 \%)$ & \\
\hline MI history other than index ACS, n (\%) & $402(20 \%)$ & $450(24 \%)$ & $489(25 \%)$ & $<0.001$ \\
\hline Stroke history, n (\%) & $73(4 \%)$ & $106(6 \%)$ & $135(7 \%)$ & $<0.001$ \\
\hline Heart failure history, n (\%) & $436(22 \%)$ & $469(25 \%)$ & $412(21 \%)$ & 0.030 \\
\hline Coronary revascularization history, n (\%) & $1449(72 \%)$ & $1241(65 \%)$ & $1391(72 \%)$ & $<0.001$ \\
\hline STEMI at index event, $\mathrm{n}(\%)$ & 1088 (54\%) & $798(42 \%)$ & $687(36 \%)$ & $<0.001$ \\
\hline Left ventricular ejection fraction ${ }^{\mathrm{a}}$ (percent) & $48 \pm 13$ & $52 \pm 12$ & $52 \pm 11$ & $<0.001$ \\
\hline Insulin, n (\%) & $733(37 \%)$ & $729(38 \%)$ & $819(42 \%)$ & $<0.001$ \\
\hline Statin, n (\%) & 1889 (94\%) & $1755(92 \%)$ & $1788(92 \%)$ & 0.024 \\
\hline Beta blocker, n (\%) & $1691(84 \%)$ & $1597(84 \%)$ & $1665(86 \%)$ & 0.10 \\
\hline Calcium channel blocker, n (\%) & $224(11 \%)$ & $428(22 \%)$ & $629(33 \%)$ & $<0.001$ \\
\hline Diuretic, n (\%) & $727(36 \%)$ & $728(38 \%)$ & $853(44 \%)$ & $<0.001$ \\
\hline ACE inhibitor, n (\%) & $1233(61 \%)$ & $1164(61 \%)$ & $1135(59 \%)$ & 0.17 \\
\hline ARB, n (\%) & $418(21 \%)$ & $503(26 \%)$ & $634(33 \%)$ & $<0.001$ \\
\hline Alpha blocker, n (\%) & $89(4 \%)$ & $67(4 \%)$ & $102(5 \%)$ & 0.029 \\
\hline Potassium sparing agents, n (\%) & $367(18 \%)$ & $268(14 \%)$ & $220(11 \%)$ & $<0.001$ \\
\hline
\end{tabular}

Unless stated otherwise, values are mean \pm SD or $\mathrm{n}(\%)$

$A C E$ angiotensin converting enzyme, $A C S$ acute coronary syndrome, $A R B$ angiotensin receptor blocker, $B M I$ body mass index, $B N P$ brain-type natriuretic peptide, eGFR estimated glomerular filtration rate, $H b A 1 c$ glycosylated hemoglobin, $H D L$ high density lipoprotein, $L D L$ low density lipoprotein, $M I$ myocardial infarction, $S B P$ systolic blood pressure, STEMI ST segment elevation myocardial infarction

a Data available for 3957 patients for left ventricular ejection fraction (1424 in tertile 1, 1262 in tertile 2 and 1271 in tertile 3)

differed according to prior CVD status ( $P$ for interaction $<0.001)$. The relationship between lower DBP and higher mortality was linear in patients with additional CVD (HR per $10 \mathrm{mmHg}$ lower DBP $1.82(1.40-2.36)$
$\mathrm{P}<0.001)$. For PP, there was no overall significant association with mortality (Additional file 1: Table S2), but there was a significant interaction $(P=0.036)$ between PP and prior CVD. 

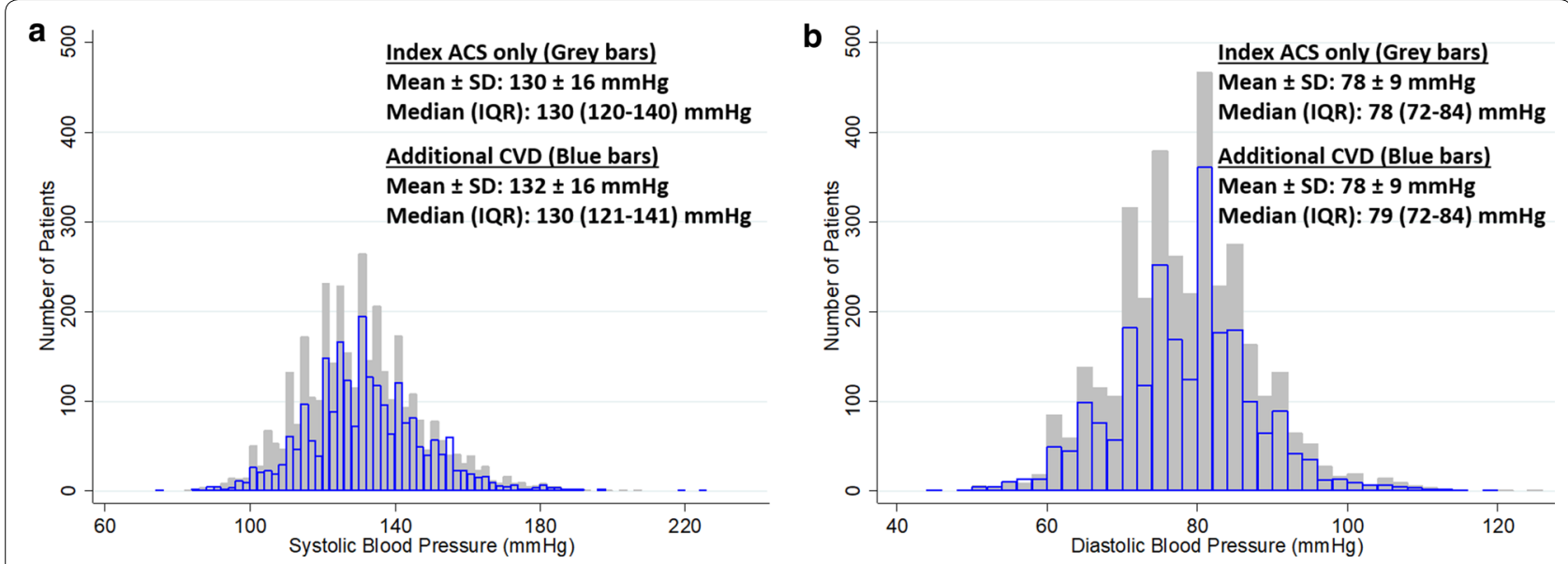

Fig. 1 Baseline distributions of systolic (a) and diastolic (b) blood pressures. Grey bars show patients with index acute coronary syndrome (ACS) only $(n=3527)$. Blue bars show patients with additional cardiovascular disease (CVD) $(n=2325)$

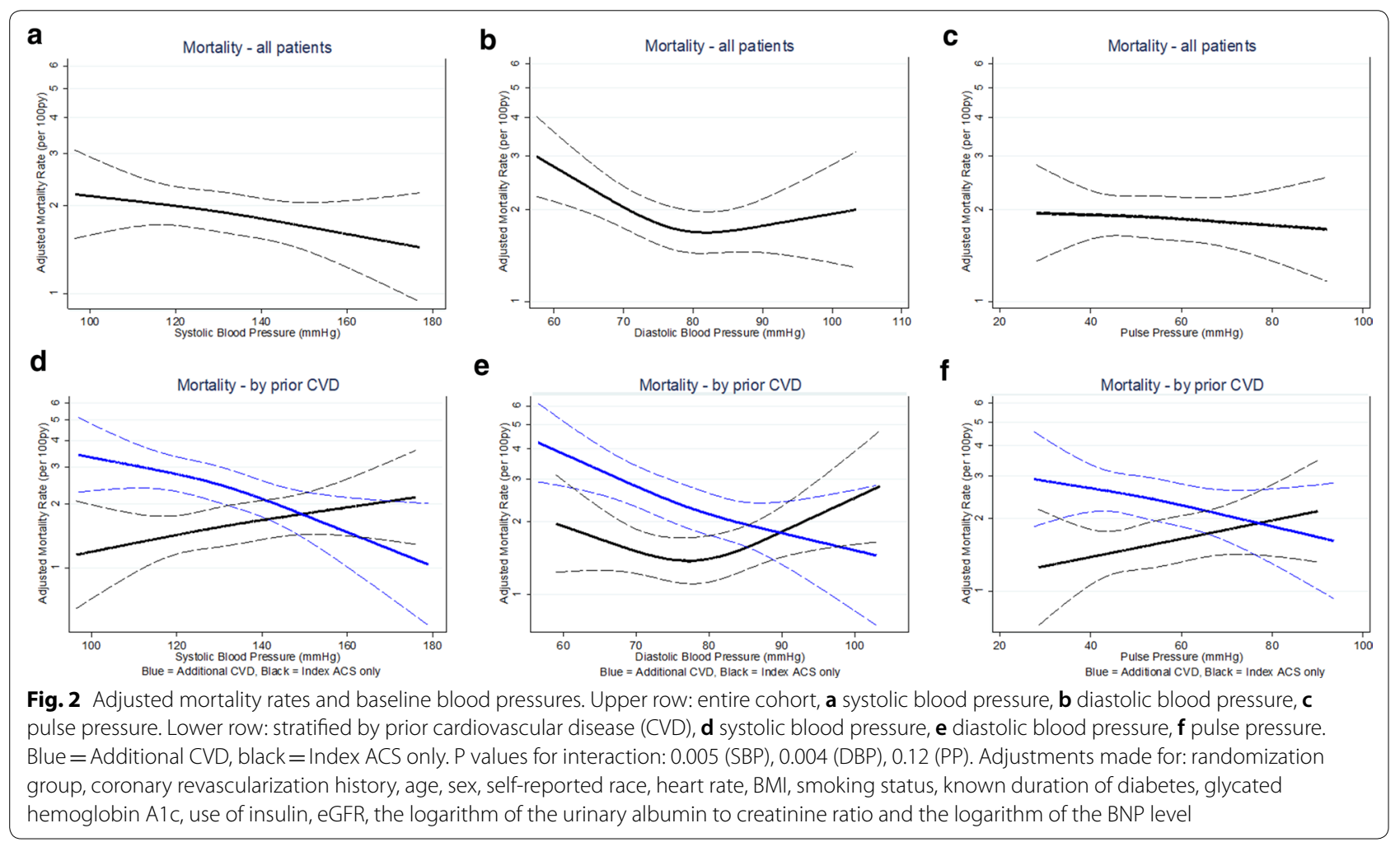

\section{Sensitivity analysis in patients with known left ventricular ejection fraction}

In this study cohort, there were 3957 patients for whom LVEF after the index ACS was available (2352/3527 in patients with index ACS only (67\%) and 1605/2325 in patients with additional CVD $(69 \%), \mathrm{P}=0.06)$. The baseline distributions of LVEF are shown graphically in Additional file 1: Figure S1 according to prior CVD status.
Mean LVEF was $53 \pm 11$ [median 53, IQR: 45-60] percent in patients with index ACS only and $48 \pm 13$ [median 50, IQR: 40-57] percent in patients with additional CVD, $\mathrm{P}<0.001$. There were 167 deaths in the group with additional CVD (4.7 deaths per 100 patient-years) and 115 deaths (2.2 deaths per 100 patient-years) in the group with index ACS only, $\mathrm{P}<0.001$. We performed a sensitivity analysis in these patients, in which we additionally 
Table 3 Adjusted hazard ratios associated with $10 \mathrm{mmHg}$ lower blood pressure

\begin{tabular}{|c|c|c|c|c|}
\hline & $\begin{array}{l}\text { Overall }(n=5852) \\
\text { HR }(95 \% \mathrm{Cl}) \mathrm{P} \\
\text { Per } 10 \mathrm{mmHg} \downarrow\end{array}$ & $\begin{array}{l}\text { Index ACS only }(n=3527) \\
\text { HR }(95 \% \text { CI) P } \\
\text { Per } 10 \mathrm{mmHg} \downarrow\end{array}$ & $\begin{array}{l}\text { Additional CVD }(n=2325) \\
\text { HR }(95 \% \mathrm{Cl}) \mathrm{P} \\
\text { Per } 10 \mathrm{mmHg} \downarrow\end{array}$ & $P$ for interaction \\
\hline Systolic blood pressure & $1.05(0.99-1.12) P=0.10$ & $0.95(0.86-1.04) P=0.26$ & $1.13(1.04-1.22) P=0.002$ & 0.005 \\
\hline Diastolic blood pressure & * & $0.94(0.79-1.12) P=0.48$ & $1.30(1.13-1.49) P<0.001$ & 0.004 \\
\hline For $\mathrm{DBP}<80 \mathrm{mmHg}$ & $1.30(1.11-1.51) P=0.001$ & - & - & \\
\hline For $\mathrm{DBP} \geq 80 \mathrm{mmHg}$ & $0.91(0.74-1.13) P=0.39$ & - & - & \\
\hline Pulse pressure & $1.02(0.94-1.10) P=0.65$ & $0.95(0.84-1.07) P=0.36$ & $1.07(0.97-1.18) P=0.19$ & 0.12 \\
\hline
\end{tabular}

* Denotes significantly non-linear associations, where two separate hazard ratios (obtained by piece-wise Cox regression) are reported. Adjustments made for: randomization group, coronary revascularization history, age, sex, self-reported race, heart rate, BMI, smoking status, known duration of diabetes, glycated hemoglobin A1C, use of insulin, eGFR, the logarithm of the urinary albumin to creatinine ratio and the logarithm of the BNP level

adjusted for LVEF. Overall, lower systolic blood pressure was significantly associated with higher mortality (HR per $10 \mathrm{mmHg}$ lower SBP: $1.09(1.01-1.18) \mathrm{P}=0.028)$. The relationship between SBP and mortality differed according to prior CVD status ( $\mathrm{P}$ for interaction 0.020) such that in patients with additional CVD, lower SBP was associated with higher mortality (HR per $10 \mathrm{mmHg}$ lower SBP: 1.18 (1.07-1.32) $\mathrm{P}=0.001$, whereas in patients with index ACS only, there was no significant relationship between SBP and mortality (Additional file 1: Table S3). For DBP, overall, there was a significant linear relationship between lower DBP and higher mortality (HR per $10 \mathrm{mmHg}$ lower DBP: $1.17(1.02-1.34) \mathrm{P}=0.025)$. As in the original cohort, the association between DBP and mortality also differed according to prior CVD status (P for interaction 0.022). In patients with additional CVD, there was a significant linear association between lower DBP and higher mortality (HR per $10 \mathrm{mmHg}$ lower DBP: $1.34(1.12-1.60) \mathrm{P}=0.001)$ whereas in patients with index ACS only, there was no significant association between DBP and mortality (Additional file 1: Table S3). For PP, there was no overall significant association with mortality and no significant interaction between prior CVD and PP (Additional file 1: Table S3).

\section{Discussion}

\section{Main findings}

The main finding of this study was that in ELIXA participants with type 2 diabetes and a recent acute coronary event, there were no overall significant relationships between SBP or PP and mortality, but there was a nonlinear relationship between DBP and mortality, such that lower DBP was associated with higher mortality for DBP levels lower than $80 \mathrm{mmHg}$ and no significant relationship was observed for DBP values of $80 \mathrm{mmHg}$ and higher. However, a greater burden of CVD, as defined by prior CVD in addition to the index event, modified the relationship between blood pressure and risk of death. Independently of several known predictors of death, lower baseline SBP or lower baseline DBP were significantly associated with higher mortality in patients with a history of additional CVD, but not in patients without additional prior CVD. A greater burden of CVD modified the relationship between blood pressure and risk of death also in a sensitivity analysis in which patients with heart failure were excluded, and in a sensitivity analysis of patients for whom additional adjustment for LVEF was made. Compared with patients with additional CVD, patients without additional CVD had lower systolic blood pressure and a more favorable risk factor profile: they were, on average, younger, had lower BMI, higher eGFR, shorter duration of diabetes, and were less often treated with insulin despite having similar HbAlc, and more often treated with a statin. These differences may have contributed to the lower event rates in the group without additional CVD and may explain why patients with additional CVD appeared to be more vulnerable to the detrimental effects of low blood pressure.

\section{Effects of lower blood pressure in coronary artery disease}

Coronary perfusion occurs mainly during diastole, and lower diastolic blood pressure has been associated with higher odds for angina in patients with coronary artery disease [19]. Diabetes status has been shown to modify the relationship between diastolic blood pressure and collateral flow index in patients with chronic total occlusion, so that at various degrees of stenosis of the predominant collateral donor artery, the collateral flow index decreased more with decreasing diastolic blood pressure in patients with diabetes than in patients without diabetes [20]. This suggests that in patients with coronary artery disease, lower diastolic blood pressure may be even more important as a risk factor in patients who also have diabetes. In patients with stable coronary artery disease who participated in the INVEST (International Verapamil SR-Trandolapril Study) trial, there was a linear relationship between lower diastolic blood pressure and lower risk for cardiovascular events or death in patients 
who had undergone coronary artery by-pass graft surgery only, whereas in all other patients, the relationship was J-shaped, with increasing risk in patients with lower diastolic blood pressure [21]. In INVEST, the prevalence of angina was also lower in patients with a history of coronary artery by-pass graft surgery [21]. This may suggest that in patients with stable coronary artery disease, those who have undergone more complete revascularization may tolerate lower diastolic blood pressure better. This hypothesis is indirectly supported by the present study, in which lower diastolic blood pressure was significantly associated with higher mortality only in patients with additional CVD, a group of patients who were also less likely to have had prior coronary revascularizations.

\section{Randomized trials of blood pressure targets in diabetes}

In patients with diabetes, randomized trials that compared different blood pressure treatment targets have not shown a clear benefit of lower treatment targets on survival [22-24]. Benefits on combined morbidity and mortality outcomes were observed in the UKPDS (United Kingdom Prospective Diabetes Study) trial where average baseline blood pressure was 160/94 $\mathrm{mmHg}$ [22], and in a subgroup of the HOT (Hypertension Optimal Treatment) trial where the baseline DBP inclusion criteria was $100-115 \mathrm{mmHg}$ [23], but not in the more recent ACCORD (Action to Control Cardiovascular Risk in Diabetes) trial, where average baseline blood pressure was $139 / 76 \mathrm{mmHg}$ [24] and in which a systolic treatment target of less than $120 \mathrm{mmHg}$ did not influence the risk for major cardiovascular events compared with a treatment target of less than $140 \mathrm{mmHg}$. One meta-analysis showed that in patients with diabetes, initiation of antihypertensive treatment provided clinical benefit only in patients with pre-treatment $\mathrm{SBP} \geq 140 \mathrm{mmHg}$, and that treatment intensification actually increased the risk for cardiovascular death in patients with SBP less than $140 \mathrm{mmHg}$ [25]. The results of the present study are observational and should not be interpreted as evidence for or against intensified blood pressure treatment in patients with diabetes. However, the results do suggest that an association between lower SBP and higher risk for death may be confined to patients with more advanced cardiovascular disease burden, and that elevated blood pressure may be a more important risk factor in patients without prior cardiovascular events. Importantly, our results should not discourage the use of blood pressure-lowering medications known to prolong survival. For instance, in patients with heart failure who participated in the CHARM (Candesartan in Heart Failure Assessment of Reduction in Mortality and Morbidity) trials, lower baseline blood pressure was also associated with higher risk for death, but the benefits of treatment with candesartan were not affected by baseline blood pressure levels [26].

\section{Observational studies of blood pressure levels and risk in diabetes}

In a secondary analysis of high risk patients with both type 2 diabetes, hypertension and coronary artery disease who participated in the HIJ-CREATE (The Heart Institute of Japan Candesartan Randomized Trial for Evaluation in Coronary Artery Disease) trial, achievement of strict systolic blood pressure control was not associated with cardiovascular risk [27]. Other observational studies of patients with type 2 diabetes and cardiovascular risk factors have reported associations between lower blood pressure levels and worse outcomes $[8-10,12]$ but differ from the present analysis in several important aspects. In an observational subgroup analysis of the INVEST trial, which included patients with diabetes and stable coronary artery disease, there was not a statistically significant increase in adjusted mortality rates for patients who achieved and maintained SBP less than $130 \mathrm{mmHg}$ compared with patients who achieved and maintained SBP less than $140 \mathrm{mmHg}$. However, patients with more than one cardiovascular event were not reported separately [8]. Observational data from two recent trials of inhibitors of dipeptidyl-peptidase 4 have revealed U-shaped relationships between SBP and adjusted CVD rates in patients with type 2 diabetes and established cardiovascular disease or multiple risk factors $[9,10]$ but did not evaluate the risk of death. In patients with diabetes and high cardiovascular risk who participated in the ONTARGET/TRANSCEND (Ongoing Telmisartan Alone and in Combination with Ramipril Global Endpoint Trial/Telmisartan Randomised Assessment Study in Angiotensin Converting Enzyme Inhibitor Intolerant Subjects with Cardiovascular Disease) trials, on-treatment SBP less than $120 \mathrm{mmHg}$ was associated with higher risk for cardiovascular events and for death, but that study excluded patients with symptomatic heart failure [12]. Another important difference between the present study and those previously cited $[8-10,12,27]$ is that we included patients in the early phase after an ACS hospitalization. To the best of our knowledge, only one large study [11] has previously described the relationship between blood pressure and mortality in a similar cohort of patients with type 2 diabetes who recently had been hospitalized with an ACS. In the EXAMINE (Examination of Cardiovascular Outcomes with Alogliptin Versus Standard of Care) trial, baseline SBP less than $120 \mathrm{mmHg}$ or baseline DBP less than $70 \mathrm{mmHg}$ were associated with higher adjusted mortality rates [11]. In ELIXA, we observed similar associations between lower blood pressure and higher mortality only in patients with additional CVD. The reason 
for this observation remains speculative but may be due to the more extensively adjusted model that was used in the current analysis, which included baseline levels of BNP, a known independent predictor of death with high discriminatory ability [18].

\section{Study limitations}

The most important study limitation is the observational study design, which implies that the described associations do not necessarily represent causal relationships. Although the associations between lower SBP or lower DBP with higher mortality were independent of several known predictors of death, this study did not address potential pathophysiological mechanisms that might explain the relationship between blood pressure and mortality. It is possible that patients with lower blood pressure had other concomitant risk factors that influenced their prognosis. For instance, poor general health, falls and increased arterial stiffness may have contributed but were not measured in the ELIXA trial. Therefore, the present analysis should not be mistaken for a randomized trial of appropriate blood pressure targets, and the results should be interpreted in the context of individualized risk stratification rather than in the context of determining optimal blood pressure treatment targets. Another limitation of the present study was that information regarding coronary anatomy or measurements of coronary artery disease severity were not collected. Inter-arm blood pressure differences are known to be associated with coronary artery disease severity [28] and to predict adverse cardiovascular events in patients with coronary artery disease [29], but were not assessed in ELIXA. Furthermore, LVEF was not available for all patients, and determination of LVEF was made by each study site and not by a core laboratory. Finally, the follow-up period was relatively short, there were few female participants, and the study instructions stated that blood pressure measurements should be performed in the supine rather than in the seated position.

\section{Conclusions}

In this analysis of ELIXA participants with type 2 diabetes and a recent coronary event, a history of additional CVD modified the relationships between SBP or DBP and mortality. Independently of known predictors of death, lower SBP or lower DBP were significantly associated with higher mortality in patients with a history of additional CVD, but not in patients without additional CVD. These findings suggest that patients with a history of multiple cardiovascular events may be more vulnerable to detrimental effects of low blood pressure. When blood pressures measured after an acute coronary event are used to assess the risk of death in patients with type
2 diabetes, the cardiovascular history needs to be taken into consideration.

\section{Supplementary information}

Supplementary information accompanies this paper at https://doi. org/10.1186/s12933-020-01150-0.

Additional file 1. Additional tables and figure.

\section{Abbreviations}

ACCORD: Action to control cardiovascular risk in diabetes; ACS: Acute coronary syndrome; BNP: Brain natriuretic peptide; CHARM: Candesartan in heart failure assessment of reduction in mortality and morbidity; Cl: Confidence interval; CVD: Cardiovascular disease; DBP: Diastolic blood pressure; eGFR: Estimated glomerular filtration rate; ELIXA: Evaluation of lixisenatide in acute coronary syndrome; EXAMINE: Examination of cardiovascular outcomes with alogliptin versus standard of care; HIJ-CREATE: The heart institute of Japan candesartan randomized trial for evaluation in coronary artery disease; HOT: Hypertension optimal treatment; HR: Hazard ratio; INVEST: International verapamil SR-trandolapril study; IQR: Interquartile range; ONTARGET: Ongoing telmisartan alone and in combination with ramipril global endpoint trial; PP: Pulse pressure; SBP: Systolic blood pressure; STEMI: ST segment elevation myocardial infarction; T2DM: Type 2 diabetes mellitus; TRANSCEND: Telmisartan randomised assessment study in angiotensin converting enzyme inhibitor intolerant subjects with cardiovascular disease; UKPDS: United Kingdom prospective diabetes study.

\section{Acknowledgements}

Not applicable.

\section{Authors' contributions}

MOW, BC, and MAP designed the present study and analyzed and interpreted data and wrote the manuscript draft. RD, HG, LK, EL, APM, EW, DA, RB-L, JJM, $J P, M R, J-C T$ and SDS were involved in the protocol design, data collection and interpretation, and reviewed the manuscript. All authors read and approved the final manuscript.

\section{Funding}

The ELIXA trial was supported by Sanofi. Institutional agreement to the Brigham and Women's Hospital was received. MW is supported by grants from The Fulbright Commission, The Swedish Heart Association, The Swedish Society of Medicine and Region Östergötland, Sweden.

\section{Availability of data and materials}

The data used to support the findings of this study are available from the corresponding author upon reasonable request.

\section{Ethics approval and consent to participate}

The study was approved by the appropriate national and institutional regulatory and ethics boards and all patients provided written informed consent.

\section{Consent for publication}

Not applicable.

\section{Competing interests}

MOW has served on advisory boards or lectured for MSD, Lilly, Novo Nordisk and Sanofi, and has organized a professional regional meeting sponsored by Lilly, Rubin Medical, Sanofi, Novartis and Novo Nordisk. BC has received consulting fees for Amgen, Biogen, Corvia, Myokardia, and Novartis. RD has received speaker fees from Sanofi, Astra Zeneca and Eli Lilly. HG holds the McMaster-Sanofi Population Health Institute Chair in Diabetes Research and Care and reports research grants from Eli Lilly, AstraZeneca, Merck, Novo Nordisk and Sanofi; honoraria for speaking from AstraZeneca, Boehringer Ingelheim, Eli Lilly, Novo Nordisk, and Sanofi; and consulting fees from Abbott, AstraZeneca, Boehringer Ingelheim, Eli Lilly, Merck, Novo Nordisk, Janssen, Sanofi, and Kowa. LK has received speaker's honorarium (personal fee) from AstraZeneca, Novartis and Boehringer, unrelated to this manuscript. EL has 
received institutional funding for research grant support from Sanofi and Akebia. APM has received personal fees from Bayer, Fresenius, Novartis for participating in study committees outside the present work. EW has received speaker fees from Orion Pharma, Novartis Healthcare, Boehringer-Ingelheim, Merck. MR has received research funding through Oregon Health \& Science University: Eli Lilly, Novo Nordisk, AstraZeneca, and honoraria for consulting: Adocia, AstraZeneca, Eli Lilly, GlaxoSmithKline, Intercept, Novo Nordisk, Sanofi, Theracos. JCT has received research grants from Amarin, Astra-Zeneca, DalCor, Esperion, Ionis, RegenXBio, Sanofi and Servier; honoraria from DalCor, Sanofi and Servier; holds minor equity interest in DalCor; and is an author of a patent on pharmacogenomics-guided CETP inhibition. SDS has received research grants from Alnylam, Amgen, AstraZeneca, Bellerophon, Bayer, BMS, Celladon, Cytokinetics, Eidos, Gilead, GSK, lonis, Lone Star Heart, Mesoblast, MyoKardia, $\mathrm{NIH/NHLBI}$, Neurotronik, Novartis, Respicardia, Sanofi Pasteur, Theracos, and has consulted for Akros, Alnylam, Amgen, Arena, AstraZeneca, Bayer, BMS, Cardior, Cardurion, Corvia, Cytokinetics, Daiichi-Sankyo, Gilead, GSK, Ironwood, Merck, Myokardia, Novartis, Roche, Takeda, Theracos, Quantum Genetics, Cardurion, AoBiome, Janssen, Cardiac Dimensions, Tenaya, Sanofi-Pasteur, Dinaqor, Tremeau. MAP receives research support from Novartis, serves as a consultant for AstraZeneca, Corvidia, DalCor, GlaxoSmithKline, Novartis, Novo Nordisk, Pharmascience and Sanofi, and has equity in DalCor.

\section{Author details}

${ }^{1}$ Cardiovascular Division, Brigham \& Women's Hospital, Harvard Medical School, 75 Francis Street, Boston, MA 02115, USA. ${ }^{2}$ Department of Internal Medicine and Department of Health, Medicine and Caring Sciences, Linköping University, Norrköping, Sweden. ${ }^{3}$ Estudios Clínicos Latinoamérica, Instituto Cardiovascular de Rosario, Rosario, Argentina. ${ }^{4}$ The Population Health Research Institute and the Department of Medicine, McMaster University and Hamilton Health Sciences, Hamilton, Canada. ${ }^{5}$ Rigshospitalet Copenhagen University Hospital, Copenhagen, Denmark. ${ }^{6}$ Stanford University Medical Center, Stanford, USA. ${ }^{7}$ Maria Cecilia Hospital, GVM Care \& Research, Cotignola, Italy. ${ }^{8}$ Research Center of the Italian Association of Hospital Cardiologists, Florence, Italy. ${ }^{9}$ McGovern Medical School, University of Texas, Houston, USA. ${ }^{10}$ Massachusetts General Hospital, Harvard Medical School, Boston, USA. ${ }^{11}$ British Heart Foundation Cardiovascular Research Centre, University of Glasgow, Glasgow, UK. ${ }^{12}$ University of Washington Medical Center, Seattle, USA. ${ }^{13}$ Oregon Health and Science University, Portland, USA. ${ }^{14}$ Montreal Heart Institute, Université de Montréal, Montreal, Canada.

Received: 23 July 2020 Accepted: 1 October 2020

Published online: 12 October 2020

\section{References}

1. Rawshani A, Rawshani A, Franzen S, Sattar N, Eliasson B, Svensson AM, et al. Risk factors, mortality, and cardiovascular outcomes in patients with type 2 diabetes. N Engl J Med. 2018;379(7):633-44.

2. Saad M, Salehi N, Ding Z, Mehta JL. Blood pressure target in diabetics: how low is too low? Eur Heart J. 2019;40(25):2044-6.

3. Whelton PK, Carey RM, Aronow WS, Casey DE Jr, Collins KJ, Dennison Himmelfarb C, et al. 2017 ACC/AHA/AAPA/ABC/ACPM/AGS/APhA/ASH/ ASPC/NMA/PCNA Guideline for the Prevention, Detection, Evaluation, and Management of High Blood Pressure in Adults: A Report of the American College of Cardiology/American Heart Association Task Force on Clinical Practice Guidelines. Hypertension. 2018;71(6):e13-e115.

4. Williams B, Mancia G, Spiering W, Agabiti Rosei E, Azizi M, Burnier M, et al. 2018 ESC/ESH guidelines for the management of arterial hypertension. Eur Heart J. 2018;39(33):3021-104.

5. American Diabetes A. 10. Cardiovascular disease and risk management: standards of medical care in diabetes-2020. Diabetes Care. 2020;43(Suppl 1):S111-S13434.

6. Hagg-Holmberg S, Dahlstrom EH, Forsblom CM, Harjutsalo V, Liebkind R Putaala J, et al. The role of blood pressure in risk of ischemic and hemorrhagic stroke in type 1 diabetes. Cardiovasc Diabetol. 2019;18(1):88.

7. Adamsson Eryd S, Gudbjornsdottir S, Manhem K, Rosengren A, Svensson AM, Miftaraj M, et al. Blood pressure and complications in individuals with type 2 diabetes and no previous cardiovascular disease: national population based cohort study. BMJ. 2016;354:14070.
8. Cooper-DeHoff RM, Gong Y, Handberg EM, Bavry AA, Denardo SJ, Bakris $\mathrm{GL}$, et al. Tight blood pressure control and cardiovascular outcomes among hypertensive patients with diabetes and coronary artery disease. JAMA. 2010;304(1):61-8.

9. Navar AM, Gallup DS, Lokhnygina Y, Green JB, McGuire DK, Armstrong PW et al. Hypertension control in adults with diabetes mellitus and recurrent cardiovascular events: global results from the trial evaluating cardiovascular outcomes with sitagliptin. Hypertension. 2017;70(5):907-14.

10. Bergmark BA, Scirica BM, Steg PG, Fanola CL, Gurmu Y, Mosenzon O, et al. Blood pressure and cardiovascular outcomes in patients with diabetes and high cardiovascular risk. Eur Heart J. 2018;39(24):2255-62.

11. White WB, Jalil F, Cushman WC, Bakris GL, Bergenstal R, Heller SR, et al. Average clinician-measured blood pressures and cardiovascular outcomes in patients with type 2 diabetes mellitus and ischemic heart disease in the EXAMINE trial. J Am Heart Assoc. 2018;7(20):e009114.

12. Bohm M, Schumacher H, Teo KK, Lonn EM, Mahfoud F, Mann JFE, et al. Cardiovascular outcomes and achieved blood pressure in patients with and without diabetes at high cardiovascular risk. Eur Heart J. 2019;40(25):2032-43.

13. Vidal-Petiot E, Ford I, Greenlaw N, Ferrari R, Fox KM, Tardif JC, et al. Cardiovascular event rates and mortality according to achieved systolic and diastolic blood pressure in patients with stable coronary artery disease: an international cohort study. Lancet. 2016;388(10056):2142-52.

14. Ferreira JP, Duarte K, Pfeffer MA, McMurray JJV, Pitt B, Dickstein K, et al. Association between mean systolic and diastolic blood pressure throughout the follow-up and cardiovascular events in acute myocardial infarction patients with systolic dysfunction and/or heart failure: an analysis from the High-Risk Myocardial Infarction Database Initiative. Eur J Heart Fail. 2018;20(2):323-31.

15. Pfeffer MA, Claggett B, Diaz R, Dickstein K, Gerstein HC, Kober LV, et al. Lixisenatide in patients with type 2 diabetes and acute coronary syndrome. N Engl J Med. 2015;373(23):2247-57.

16. Bentley-Lewis R, Aguilar D, Riddle MC, Claggett B, Diaz R, Dickstein K, et al. Rationale, design, and baseline characteristics in Evaluation of LIXisenatide in Acute Coronary Syndrome, a long-term cardiovascular end point trial of lixisenatide versus placebo. Am Heart J. 2015;169(5):631-8.

17. Shin SH, Claggett B, Pfeffer MA, Skali H, Liu J, Aguilar D, et al. Hyperglycaemia, ejection fraction and the risk of heart failure or cardiovascular death in patients with type 2 diabetes and a recent acute coronary syndrome. Eur J Heart Fail. 2020. https://doi.org/10.1002/ejhf.1790.

18. Wolsk E, Claggett B, Pfeffer MA, Diaz R, Dickstein K, Gerstein HC, et al. Role of B-type natriuretic peptide and $\mathrm{N}$-terminal prohormone BNP as predictors of cardiovascular morbidity and mortality in patients with a recent coronary event and type 2 diabetes mellitus. J Am Heart Assoc. 2017;6(6):e004743.

19. Peri-Okonny PA, Patel KK, Jones PG, Breeding T, Gosch KL, Spertus JA, et al. Low diastolic blood pressure is associated with angina in patients with chronic coronary artery disease. J Am Coll Cardiol. 2018;72(11):1227-322.

20. Shen $Y$, Yang ZK, Hu J, Wang XQ, Dai Y, Zhang S, et al. Donor artery stenosis interactions with diastolic blood pressure on coronary collateral flow in type 2 diabetic patients with chronic total occlusion. Cardiovasc Diabetol. 2018;17(1):76.

21. Denardo SJ, Messerli FH, Gaxiola E, Aranda JM Jr, Cooper-Dehoff RM, Handberg EM, et al. Coronary revascularization strategy and outcomes according to blood pressure (from the International Verapamil SRTrandolapril Study [INVEST]). Am J Cardiol. 2010;106(4):498-503.

22. UK Prospective Diabetes Study Group. Tight blood pressure control and risk of macrovascular and microvascular complications in type 2 diabetes: UKPDS 38. BMJ. 1998;317(7160):703-13.

23. Hansson L, Zanchetti A, Carruthers SG, Dahlof B, Elmfeldt D, Julius S, et al. Effects of intensive blood-pressure lowering and low-dose aspirin in patients with hypertension: principal results of the Hypertension Optimal Treatment (HOT) randomised trial. HOT Study Group. Lancet. 1998:351(9118):1755-62.

24. Cushman WC, Evans GW, Byington RP, Goff DC Jr, Grimm RH Jr, Cutler JA, et al. Effects of intensive blood-pressure control in type 2 diabetes mellitus. N Engl J Med. 2010;362(17):1575-85.

25. Brunstrom M, Carlberg B. Effect of antihypertensive treatment at different blood pressure levels in patients with diabetes mellitus: systematic review and meta-analyses. BMJ. 2016;352:1717. 
26. Meredith PA, Ostergren J, Anand I, Puu M, Solomon SD, Michelson EL, et al. Clinical outcomes according to baseline blood pressure in patients with a low ejection fraction in the CHARM (Candesartan in Heart Failure: Assessment of Reduction in Mortality and Morbidity) Program. J Am Coll Cardiol. 2008;52(24):2000-7.

27. Kamishima K, Ogawa H, Jujo K, Yamaguchi J, Hagiwara N. Relationships between blood pressure lowering therapy and cardiovascular events in hypertensive patients with coronary artery disease and type 2 diabetes mellitus: the HIJ-CREATE sub-study. Diabetes Res Clin Pract. 2019;149:69-77.

28. Park SJ, Son JW, Park SM, Choi HH, Hong KS. Relationship between interarm blood pressure difference and severity of coronary atherosclerosis. Atherosclerosis. 2017;263:171-6.
29. Park SJ, Son JW, Hong KS, Choi HH. Effect of inter-arm blood pressure differences on outcomes after percutaneous coronary intervention. J Cardiol. 2020:75(6):648-53.

\section{Publisher's Note}

Springer Nature remains neutral with regard to jurisdictional claims in published maps and institutional affiliations.
Ready to submit your research? Choose BMC and benefit from:

- fast, convenient online submission

- thorough peer review by experienced researchers in your field

- rapid publication on acceptance

- support for research data, including large and complex data types

- gold Open Access which fosters wider collaboration and increased citations

- maximum visibility for your research: over 100M website views per year

At BMC, research is always in progress.

Learn more biomedcentral.com/submissions 